\title{
PERANCANGAN DAN ANALISIS PENGIRIMAN DATA DIGITAL BERBASIS VLC DENGAN LED DAN PHOTOTRANSISTOR ARRAY
}

\author{
Retno Renggani Nugroho ${ }^{1}$, Inung Wijayanto ${ }^{2}$, Sugondo Hadiyoso ${ }^{3}$ \\ ${ }^{1}$ Mahasiswa S1 Teknik Telekomunikasi Universitas Telkom \\ ${ }^{2}$ Dosen S1 Teknik Telekomunikasi Universitas Telkom \\ ${ }^{3}$ Dosen D3 Teknik Telekomunikasi Universitas Telkom \\ E-mail: rrenggani@student.telkomuniversity.ac.id
}

\begin{abstract}
Visible Light Communication (VLC) is a communication system using visible light as information carrier. The development of $V L C$ is based on the some banning of radio frequency usage and the increasing use of LEDs. LED consumes low power and has high switching speed, which suitable for transmitting data. This study designed VLC prototype with LED array and phototransistor array that sends digital data of text in various sizes. Test is done by combination of different distance and bitrate. As results, this prototype can send and receive data at distance 1-100 cm and speed 2400, 4800, and $9600 \mathrm{bps}$.
\end{abstract}

Keywords: VLC, LED, Phototransistor, Array.

\begin{abstract}
ABSTRAK
Visible Light Communication (VLC) adalah sistem komunikasi yang menggunakan cahaya tampak sebagai pembawa informasinya. Perkembangan VLC didasarkan atas pelarangan penggunaan frekuensi radio di beberapa tempat serta meningkatnya penggunaan LED. Kelebihan LED yaitu mengkonsumsumsi daya rendah serta memiliki kecepatan switching yang tinggi sehingga cocok untuk mentransmisikan data. Pada penelitian ini dirancang prototipe VLC dengan LED array dan phototransistor array. Prototipe ini mengirimkan data digital berupa teks dalam berbagai ukuran. Pengujian dilakukan dengan kombinasi jarak dan bitrate yang berbeda-beda. Prototipe dapat mengirim dan menerima data pada jarak 1-100 cm kecepatan 2400, 4800, dan 9600 bps.
\end{abstract}

Kata kunci: VLC, LED, Phototransistor, Array.

\section{PENDAHULUAN}

Teknologi nirkabel semakin berkembang dari waktu ke waktu dan gelombang radio masih menjadi pilihan utama sebagai pembawa informasi. Namun ada beberapa kelemahan gelombang radio diantaranya adalah pelarangan penggunaan frekuensi radio di beberapa tempat (UU NO 1, 2009: Pasal 54) serta semakin terbatasnya frekuensi radio yang tersedia (Denny Setiawan, 2010: 14-15). Dengan adanya permasalahan tersebut mendorong munculnya pemanfaatan pembawa informasi lain yang ada pada spektrum gelombang elektromagnetik, yaitu cahaya tampak. Teknologi yang menggunakan cahaya tampak sebagai pembawa informasi disebut Visible Light Communication (VLC).
Semakin maraknya penggunaan LED dikalangan masyarakat menjadi pendukung berkembangnya VLC. Cahaya tampak yang digunakan pada VLC bersumber dari LED. LED dipakai karena memiliki kecepatan switching yang tinggi, mengkonsumsi daya rendah, dan murah, sehingga cocok jika digunakan sebagai bagian dari teknologi komunikasi nirkabel cahaya tampak ini (Sumit Jaykant Meshram, 2016: 1). Teknologi ini merupakan pengembangan teknologi serat optik yang menggunakan cahaya sebagai pembawa informasi melalui media transmisi berbahan kaca, sehingga sangat mungkin jika cahaya tampak dari LED dapat pula mengirimkan informasi dimana media transmisinya adalah udara seperti pada teknologi wireless sebelumnya yang mengggunakan gelombang radio sebagai pambawanya. 


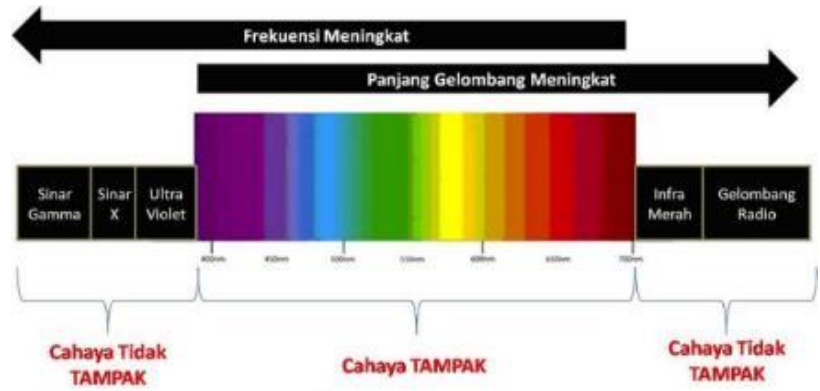

Gambar 1. Spektrum gelombang elektromagnetik

Penelitian ini merancang sebuah prototipe berupa transceiver, dimana perangkat dapat berperan baik sebagai pengirim maupun penerima. Penelitian ini merupakan pengembangan dari penelitian sebelumnya (Nenggala Yudhabrama, 2017: 60) dimana prototipe hanya dapat melakukan pengiriman data sejauh $15 \mathrm{~cm}$ dengan kecepatan $4800 \mathrm{bps}$, 9600 bps, dan 19200 bps. Pada prototipe ini,di bagian pengirim terdapat LED array yang memancarkan cahaya tampak untuk mengirimkan data digital berupa teks, data tersebut kemudian diterima oleh phototransistorarray di bagian penerimannya. Dari prototipe ini akan dianalisa pengaruh jarak dan bitrate pada pengiriman data digital berupa teks yang mempunyai ukuran berbeda-beda.

\section{Visible Light Communication}

Visible Light Communication (VLC) merupakan salah satu jenis sistem komunikasi optik unguided yang menggunakan cahaya tampak sebagai pembawa informasi, udara sebagai media transmisi, dan phototransistor sebagai komponen penerimanya (Liju Sajan, 2015: 53). Pada frekuensi gelombang elektromagnetik, cahaya tampak mempunyai rentang frekuensi $430 \mathrm{THZ}-750 \mathrm{THz}$, dimana rentan frekuensi tersebut lebih besar daripada rentan frekuensi gelombang radio $3 \mathrm{kHZ}-300$ GHZ. Dengan rentan frekuensi yang besar membuat cahaya tampak mempunyai bandwith yang lebar serta dapat mengakomodasi lebih banyak user dan juga berpotensi mempunyai kecepatan transfer data yang tinggi (Liju Sajan, 2015: 53). Pengembangan VLC lebih difokuskan untuk pengaplikasian indoor.

\section{Light Emitting Diode}

Light Emitting Diode (LED) adalah komponen elektronika yang mengemisi cahaya dari arus yang diterima (Keiser Gerd, 2000: 139). Lampu LED sudah banyak digunakan masyarakat sebagai sumber penerangan pengganti lampu neon karena sifatnya yang hemat daya dan murah. LED akan menyala ketika mengirimkan logika 1 dan mati ketika mengirimkan logika 0 . LED mempunyai kecepatan switching yang sangat cepat hingga tidak dapat terlihat langsung oleh mata kita. Di dalam LED terdapat sambungan semikonduktor tipe-p dan semikonduktor tipe-n yang diberi forward bias. Elektron akan berada pada pita valensi apabila tidak ada arus yang mengalir, namun apabila arus yang diberikan memiliki energi yang lebih besar daripada energy gap maka elektron-elektron yang berada pada pita valensi akan berpindah ke pita konduksi. Emisi LED termasuk emisi spontan, hal tersebut yang menyebabkan pancaran cahaya LED bersifat menyebar.

\section{Phototransistor}

Transistor yang dapat mengubah energi cahaya menjadi energi listrik dan mempunyai penguat internal disebut phototransistor. Cara kerja phototransistor hampir sama dengan transistor lain, arus pada basis transistor dikalikan untuk memberikan arus pada kolektor. Pada phototransistor, arus basis dikendalikan oleh jumlah cahaya yang diterimanya. Dengan demikian, phototransistor biasanya hanya memiliki dua kaki yaitu kolektor dan emitor, untuk terminal basisnya berbentuk lensa yang berfungsi sebagai sensor pendeteksi cahaya. Arus yang mengalir dari kolektor ke emitor akan semakin besar apabila terminal basis pada phototransistor menerima intensitas cahaya yang tinggi.

\section{Komunikasi Serial RS 232}

Transfer data dalam sebuah sistem umumnya dilakukan secara paralel. Bit-bit data yang akan dikirim secara paralel pada waktu 
yang sama melalui suatu sistem digital. Untuk mentransfer data pada jarak jauh lebih baik mengirimkan data dalam bentuk serial. Data yang dikirim dari sistem dikonversi menjadi bit serial dan satu bit ditransfer pada satu jalur ke sistem penerima pada satu waktu. Pada penerima, data akan direkonstruksi dari serial menjadi paralel (Liju Sajan, 2015: 53). Prinsip komunikasi RS 232 adalah komunikasi asinkron, dimana sinyal clock pada komunikasi ini tidak disertakan bersama data namun dibangkitkan pada masing-masing pengirim dan penerima. Untuk melakukan sinkronisasi maka setiap kali pengiriman data disertakan sebuah start bit dan sebuah stop bit. Maka frame data yang dikirimkan susunannya adalah start bit, bit-bit data, paritas dan diakhiri dengan stop bit. Kecepatan transfer data pada komunikasi serial asinkron cukup beragam, 2400, 4800, 9600, 19200 bps. Komponen yang biasa dipakai sebagai penghubung RS 232 adalah konektor DB9.

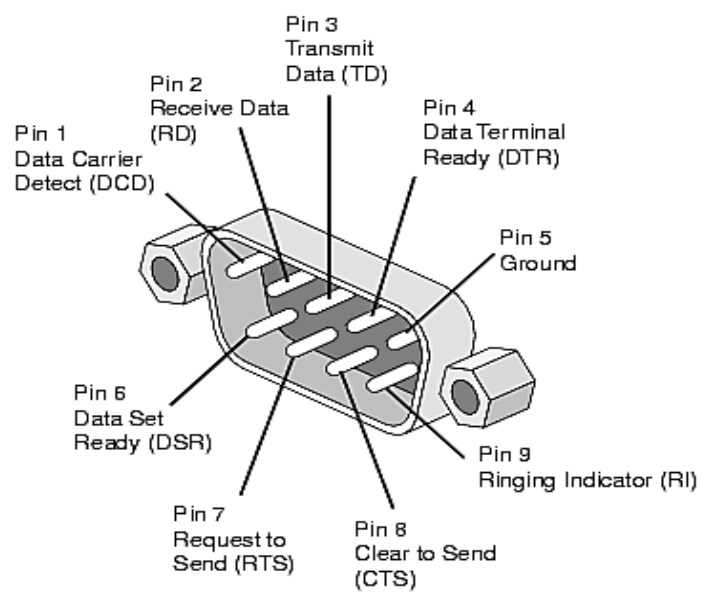

Gambar 2. Fungsi dari setiap pin DB9

(www.db9-pinout.com, 2014)

\section{LED dan Phototransistor Array}

LED yang disusun array dapat mendukung beberapa aliran data bersamaan serta memberikan intensitas iluminasi yang memadai (Chaopei Wu, 2014: 1). Dengan disusunnya LED array maka akan memperluas jangkauan pancaran dari LED. Phototransistor yang juga disusun array akan memiliki cakupan daerah penerimaan yang lebih luas pula.

\section{METODE}

Perancangan sistem komunikasi berbasis cahaya tampak ini dimulai dari studi kepustakaan guna mempelajari teori mengenai komponen-komponen yang akan digunakan untuk merancang prototipe VLC serta komunikasi serial. Langkah selanjutnya yang dilakukan adalah analisis perancangan perangkat keras sesuai dengan ilmu yang telah didapatkan dari studi kepustakaan sebelumnya. Setelah menganalisis rangkaian perangkat keras, maka dilakukan implementasi perangkat keras. Tahapan terakhir yang dilakukan adalah menganalisis performansi perangkat keras dengan melakukan beberapa percobaan pada ukuran data dengan kombinasi jarak dan kecepatan yang berbeda-beda.

\section{Perancangan Sistem}

Sistem menggunakan dua prototipe berupa transceiver, sehingga masing-masing prototipe dapat melakukan pengiriman (transfer) maupun penerimaan (receive) informasi. Kedua prototipe masing-masing dihubungkan ke sebuah Personal Computer (PC) yang telah terpasang perangkat lunak berupa aplikasi antarmuka untuk memudahkan user dalam melakukan pengiriman data. Untuk menghubungkan antara prototipe dengan PC digunakan konektor DB9. Model sistem dari prototipe yang dirancang dapat dilihat pada gambar dibawah ini.

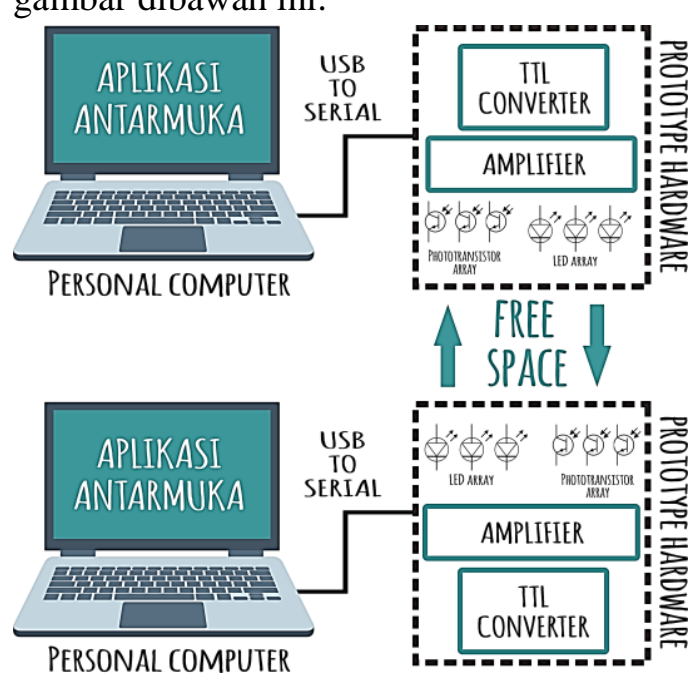

Gambar 3. Model sistem 
Dari model sistem diatas dapat diketahui aliran data awal berasal dari Personal Computer (PC). Di dalam PC terdapat aplikasi antarmuka yang menjembatani antara user dengan perangkat keras. Data dari PC dikirim melalui USB to serial ke perangkat keras, pada perancangan kali ini digunakan konektor DB9. Dari konektor DB9, data masuk ke modul RS 232 to TTL untuk mengubah tegangan RS-232 menjadi level tegangan transistor-transistor logic (TTL) agar nantinya dapat diproses lebih lanjut. Dari blok TTL converter, masuk ke blok amplifier dimana terdapat IC 7414 Scmitt Trigger hex inverter sebagai perangkat penguat. Dengan adanya proses ini maka sinyal yang masuk akan dikuatkan dan noise akan berkurang sebelum diproses lebih lanjut. Dari blok amplifier, masuk ke blok LED, sebagai penghasil cahaya tampak. Pada penelitian kali ini digunakan High Power LED 3 watt yang disusun array secara paralel, tujuannya adalah saat ada satu LED yang terputus maka LED lain akan tetap menyala. Selain hal tersebut, pada rangkaian paralel nyala lampu lebih terang daripada rangkaian seri karena arus yang didapatkan antar LED dialokasikan untuk masing-masing LED bukan untuk dibagi-bagi untuk semua LED di rangkaian seperti pada rangkaian seri. Cahaya LED akan membawa sinyal berisi informasi yang dikirimkan ke penerima.

Pada rangkaian prototipe penerima digunakan phototransistor jenis L14G1 yang disusun array sebagai penerima sinyal berisi informasi dari pengirim. Phototransistor disusun array secara paralel karena pada rangkaian paralel ketika ada satu phototransistor yang terlepas dari rangkaian maka phototransistor lain masih dapat bekerja dengan baik. Sinyal yang diterima oleh phototransistor masuk ke blok amplifier untuk dikuatkan. Dari blok amplifier, masuk ke blok TTL converter berupa modul RS 232 to TTL digunakan untuk mengubah tegangan dari sinyal yang telah dikuatkan oleh IC 7414 berupa level tegangan TTL menjadi tegangan RS-232 untuk kemudian diteruskan ke konektor
DB-9. Dari konektor DB9, informasi diteruskan ke PC dan diterjemahkan oleh aplikasi antarmuka agar dapat dibaca dengan mudah oleh user.

\section{Perancangan Perangkat Keras}

Pada bagian perangkat keras tranceiver, LED berperan sebagai sumber cahaya yang akan membawa informasi dan phototransistor berfungsi sebagai penerimanya. Selanjutnya, phototransistor akan mengubahnya menjadi sinyal listrik sebelum direkonstruksi kembali menjadi informasi awal. Selain itu, digunakan pula berbagai komponen lain seperti terlihat pada desain skematik prototipe pada gambar 3 .

Berikut ini adalah komponenkomponen yang digunakan pada masingmasing prototipe transceiver, yaitu :

- Adaptor $12 \mathrm{~V} 220 \mathrm{~mA}=1$ buah

- Kabel USB to serial = 1 buah

- Modul RS 232 to TTL = 1 buah

- Resistor $1 \mathrm{~K}=2$ buah

- Transistor BC $548=1$ buah

- Transistor DB $139=1$ buah

- IC 74LS14 = 1 buah

- High Power LED 3 watt = 3 buah

- PhototransistorL14G1 = 3 buah

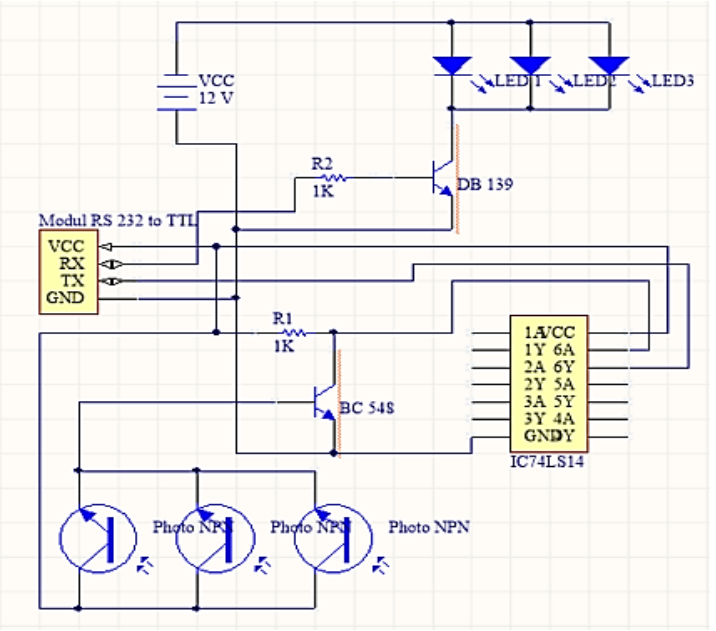

Gambar 3. Desain rangkaian

Modul RS 232 to TTL digunakan untuk mengubah tegangan RS 232 ke level tegangan TTL agar dapat diproses lebih lanjut. Sedangkan IC 74LS14 Scmitt Triggerhex inverter berfungsi sebagai amplifier. Untuk LED dan phototransistor disusun array secara 
paralel. Rangkaian paralel mempunyai beberapa kelebihan dibandingkan rangkaian seri, diantaranya adalah jika salah satu sambungan LED atau phototransistor terputus, maka komponen lain akan tetap menyala, selain itu nyala lampu pada rangkaian paralel lebih terang daripada rangkaian seri karena arus yang diterima setiap lampu sama. Keuntungan lainnya adalah tegangan yang dibutuhkan untuk mengoperasikan rangkaian paralel juga lebih rendah daripada rangkaian seri.

\section{Penguatan Pada Amplifier}

\begin{tabular}{llr}
\multicolumn{2}{c}{ Operational Amplifier } & (Op-Amp) \\
merupakan penguat tegangan & berupa \\
differensial amplifier, common emitter
\end{tabular}
amplifier dan bagian umpan balik negatif yang dibuat dalam bentuk Integrated Circuit (IC). Ada dua jenis penguatan Op-Amp, yaitu $O p$ Amp Inverting dan Op-Amp non-Inverting.

Op-Amp Inverting adalah rangkaian Op-Amp yang bekerja sebagai penguat tegangan pembalik. Hasil penguatan dari Op-Amp Inverting akan berbeda fase $180^{\circ}$ dari tegangan inputnya. Apabila input berupa tegangan positif, maka output akan berupa tegangan negatif, dan sebaliknya.

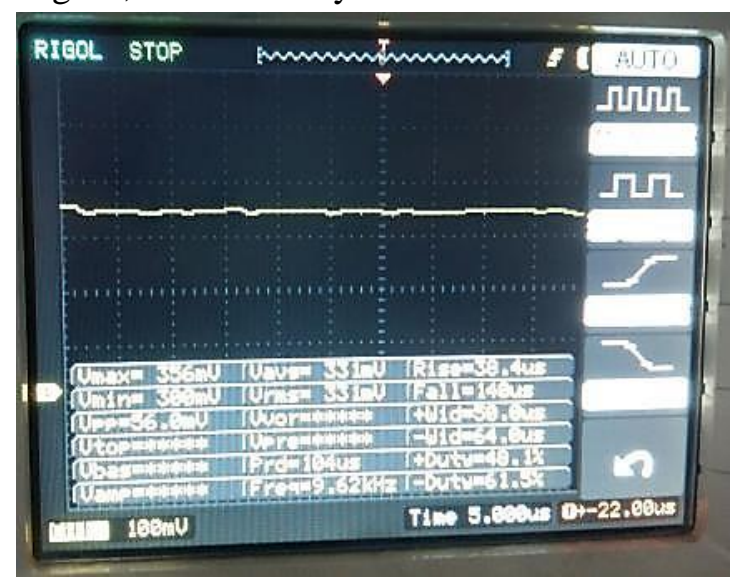

Gambar 4. Input Op-Amp inverter

Pada rangkaian digunakan amplifier berupa IC 74LS14 Scmitt Triggerhex inverter. Masukan Op-Amp sebesar $356 \mathrm{mV}$ setelah mendapat penguatan dari Op-AmpInverting tegangan berubah menjadi $-2.24 \mathrm{~V}$.

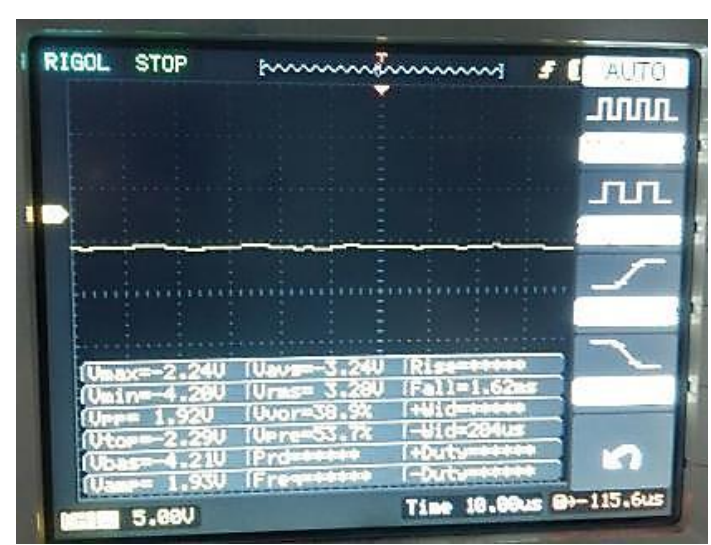

Gambar 4. Output Op-Amp inverter

\section{Aplikasi Antarmuka}

Guna mempermudah user dalam mengirimkan teks digital, digunakan aplikasi komunikasi serial Hyper Terminal. Alasan digunakannya aplikasi ini adalah aplikasi ini telah ada di masyarakat serta mudah di unduh dan digunakan oleh masyarakat. Selain kelebihan tersebut, kelebihan lain aplikasi Hyper Terminal yaitu aplikasi ini akan mencoba mengirimkan kembali file secara otomatis apabila terjadi kegagalan pengiriman. Perlu adanya beberapa pengaturan pada proses pertukaran data diantaranya adalah di sisi pengirim dan penerima baud rate besarnya harus sama. Jika besar baud rate berbeda, maka akan terjadi kegagalan pengiriman informasi.

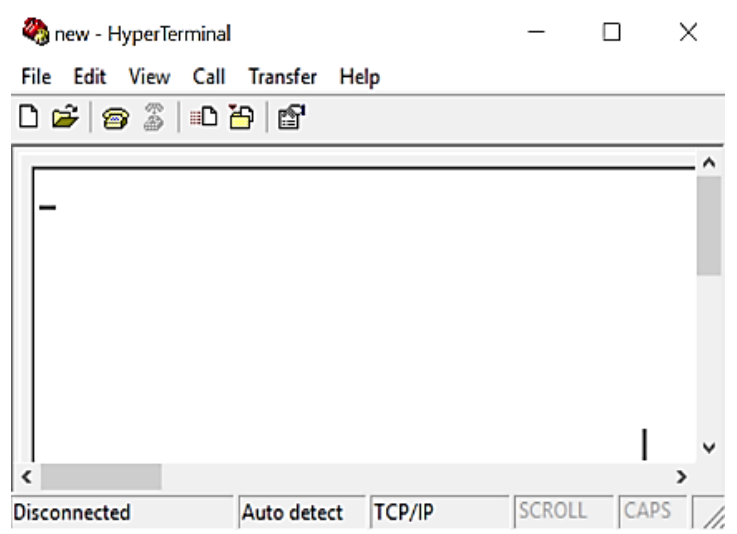

Gambar 4. Aplikasi Hyper Terminal

Melalui dialog box baud rate di aplikasi antarmuka, kita dapat memilih beberapa nilai baud rate yaitu 1200 bps, 2400 bps, 4800 bps, 9600 bps, 19200 bps, 38400 bps, dan 57600 bps. 


\section{Diagram Alir Kerja Sistem}

Gambar 4 adalah diagram alir kerja sistem mulai dari pengiriman data sampai penerimaan di sisi penerima.

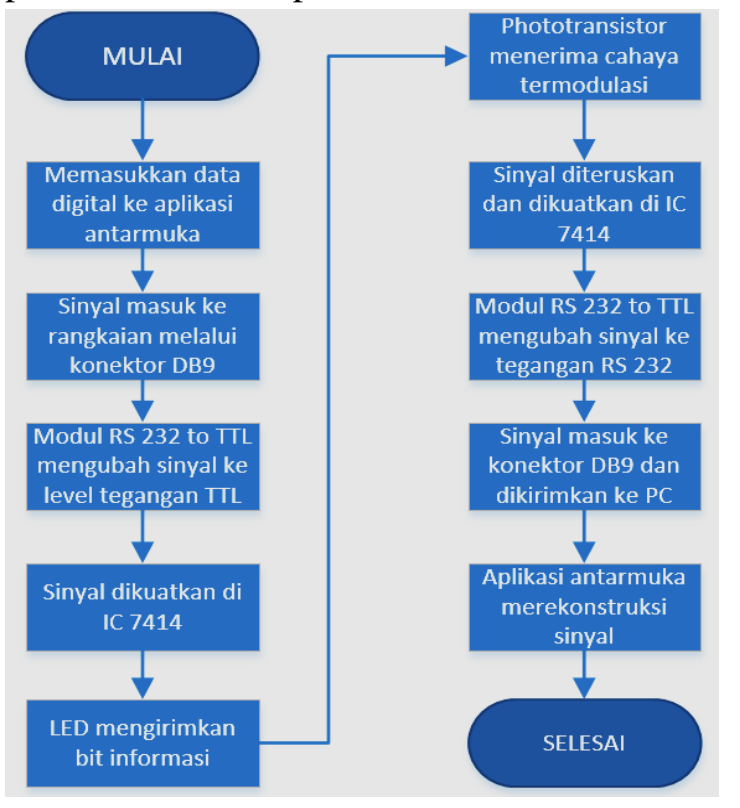

Gambar 4. Diagram kerja sistem

Proses pengiriman dimulai dari memasukkan data ke aplikasi antarmuka. Sebelum melakukan pengiriman, harus dipastikan bahwa baud rate antara pengirim dan penerima sama besar. Pada sisi penerima harus diatur lokasi yang digunakan untuk menyimpan data yang diterima sebelum melakukan penerimaan data. Setelah apliasi di sisi pengirim dan penerima telah siap, maka data siap dikirim. Data yang berasal dari PC pengirim masuk ke rangkaian melalui kabel USB to serial. Pada ujung kabel terdapat konektor untuk menghubungkan ke rangkaian, konektor tersebut adalah konektor DB9. Dari konektor DB9, sinyal masuk ke modul RS 232 to TTL, lalu modul tersebut akan merubah tegangan RS 232 ke level tegangan TTL agar dapat diproses lebih lanjut. Selanjutnya sinyal akan dikuatkan oleh amplifier. Dari amplifier, sinyal akan dikirimkan ke penerima melalui cahaya tampak yang dipancarkan oleh LED. Di sisi penerima cahaya berisi sinyal informasi akan diterima oleh phototransistor. Kemudian sinyal informasi akan diteruskan ke amplifier untuk mendapatkan penguatan. Dari amplifier sinyal masuk ke modul RS 232 to TTL untuk mendapatkan perubahan tegangan dari tegangan TTL ke tegangan RS 232. Dari modul ini, sinyal informasi masuk ke PC penerima melalui konektor DB9 dan kabel USB to serial. Di sisi penerima aplikasi antarmuka akan membaca data yang diterimanya.

\section{Skenario Pengujian}

Analisis pengujian prototipe dilakukan dengan kombinasi jarak dan bitrate yang berbeda-beda. Pengujian dilakukan dengan kombinasi jarak antara $1-100 \mathrm{~cm}$ serta kecepatan 2400, 4800, dan 9600 bps.

Pengujian dimulai dengan mengatur aplikasi antarmuka dan memastikan bahwa baud rate antara pengirim dan penerima sama besar. Percobaan dilakukan pada kecepatan 2400 bps, 4800 bps, dan 9600 bps. Langkah selanjutnya adalah mengatur jarak antara pengirim dan penerima. Jarak yang digunakan adalah $10 \mathrm{~cm}, 30 \mathrm{~cm}, 70 \mathrm{~cm}$, dan yang tarakhir $100 \mathrm{~cm}$. Setelah itu pengujian dilakukan dengan memilih file berukuran $80 \mathrm{~KB}$ untuk 12 kali percobaan pertama, $500 \mathrm{~KB}$ untuk 12 kali percobaan selanjutnya dan $1500 \mathrm{~KB}$ untuk percobaan terakhir. Setelah memilih ukuran file, maka sistem siap mengirimkan data digital berupa teks ke penerima.

Percobaan dianggap berhasil apabila telah dipastikan file yang dikirim dari PC pengirim ada di PC penerima dan tidak mengalami kerusakan. Setelah dipastikan bahwa file tidak mengalami kerusakan, maka langkah selanjutnya adalah melakukan pencatatan hasil percobaan. 


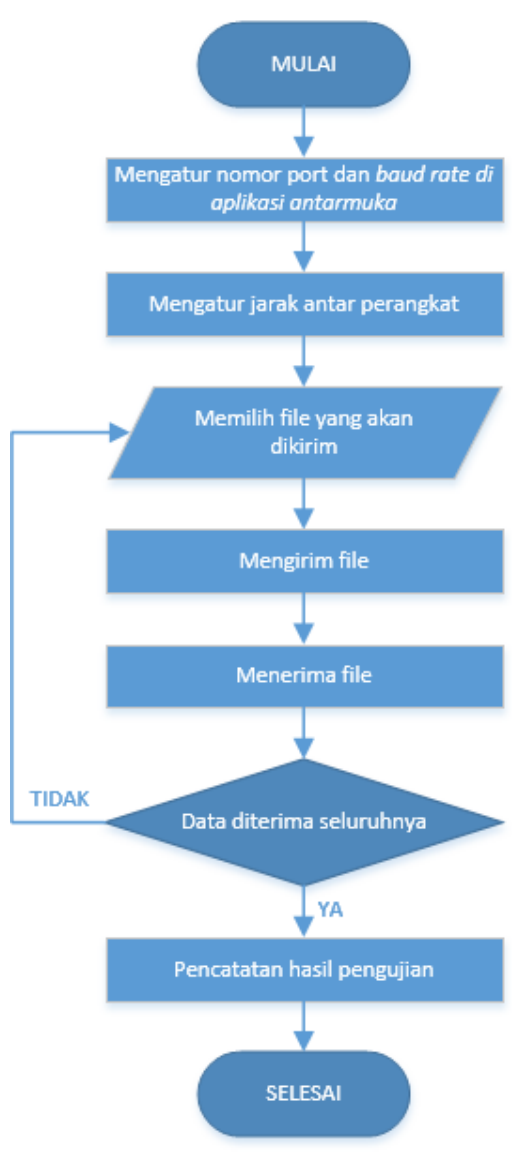

Gambar 5. Diagram alir pengujian

\section{HASIL DAN PEMBAHASAN}

Dari pengujian prototipe telah dipastikan bahwa data digital berupa teks yang dikirim, diterima tanpa adanya kerusakan di sisi penerima dan didapatkan data yang disajikan pada tabel 1.

Tabel 1. Hasil pengujian prototipe

\begin{tabular}{|c|c|c|c|c|}
\hline No & $\begin{array}{c}\text { Ukuran } \\
\text { file }\end{array}$ & $\begin{array}{c}\text { Baud } \\
\text { rate }\end{array}$ & Jarak & Ket \\
\hline 1. & \multirow[t]{11}{*}{$80 \mathrm{~KB}$} & \multirow[t]{4}{*}{2400} & $10 \mathrm{~cm}$ & Berhasil \\
\hline 2. & & & $30 \mathrm{~cm}$ & Berhasil \\
\hline 3. & & & $70 \mathrm{~cm}$ & Berhasil \\
\hline 4. & & & $100 \mathrm{~cm}$ & Berhasil \\
\hline 5. & & \multirow[t]{4}{*}{4800} & $10 \mathrm{~cm}$ & Berhasil \\
\hline 6. & & & $30 \mathrm{~cm}$ & Berhasil \\
\hline 7. & & & $70 \mathrm{~cm}$ & Berhasil \\
\hline 8. & & & $100 \mathrm{~cm}$ & Berhasil \\
\hline 9. & & \multirow[t]{3}{*}{9600} & $10 \mathrm{~cm}$ & Berhasil \\
\hline 10. & & & $30 \mathrm{~cm}$ & Berhasil \\
\hline 11. & & & $70 \mathrm{~cm}$ & Berhasil \\
\hline
\end{tabular}

\begin{tabular}{|c|c|c|c|c|}
\hline No & $\begin{array}{c}\text { Ukuran } \\
\text { file }\end{array}$ & $\begin{array}{l}\text { Baud } \\
\text { rate }\end{array}$ & Jarak & Ket \\
\hline 12. & & & $100 \mathrm{~cm}$ & Gagal \\
\hline 13. & \multirow[t]{12}{*}{$500 \mathrm{~KB}$} & \multirow[t]{4}{*}{2400} & $10 \mathrm{~cm}$ & Berhasil \\
\hline 14. & & & $30 \mathrm{~cm}$ & Berhasil \\
\hline 15. & & & $70 \mathrm{~cm}$ & Berhasil \\
\hline 16. & & & $100 \mathrm{~cm}$ & Berhasil \\
\hline 17. & & \multirow[t]{4}{*}{4800} & $10 \mathrm{~cm}$ & Berhasil \\
\hline 18. & & & $30 \mathrm{~cm}$ & Berhasil \\
\hline 19. & & & $70 \mathrm{~cm}$ & Berhasil \\
\hline 20. & & & $100 \mathrm{~cm}$ & Berhasil \\
\hline 21. & & \multirow[t]{4}{*}{9600} & $10 \mathrm{~cm}$ & Berhasil \\
\hline 22. & & & $30 \mathrm{~cm}$ & Berhasil \\
\hline 23. & & & $70 \mathrm{~cm}$ & Gagal \\
\hline 24. & & & $100 \mathrm{~cm}$ & Gagal \\
\hline 25. & \multirow[t]{12}{*}{$1500 \mathrm{~KB}$} & \multirow[t]{4}{*}{2400} & $10 \mathrm{~cm}$ & Berhasil \\
\hline 26. & & & $30 \mathrm{~cm}$ & Berhasil \\
\hline 27. & & & $70 \mathrm{~cm}$ & Berhasil \\
\hline 28. & & & $100 \mathrm{~cm}$ & Berhasil \\
\hline 29. & & \multirow[t]{4}{*}{4800} & $10 \mathrm{~cm}$ & Berhasil \\
\hline 30. & & & $30 \mathrm{~cm}$ & Berhasil \\
\hline 31. & & & $70 \mathrm{~cm}$ & Berhasil \\
\hline 32. & & & $100 \mathrm{~cm}$ & Berhasil \\
\hline 33. & & \multirow[t]{4}{*}{9600} & $10 \mathrm{~cm}$ & Berhasil \\
\hline 34. & & & $30 \mathrm{~cm}$ & Berhasil \\
\hline 35. & & & $70 \mathrm{~cm}$ & Gagal \\
\hline 36. & & & $100 \mathrm{~cm}$ & Gagal \\
\hline
\end{tabular}

\section{SIMPULAN}

Dari hasil pengujian prototipe didapatkan hasil bahwa prototipe VLC dengan LED array dan phototransistor array dapat meningkatkan jangkauan jarak pengiriman dibandingkan dengan VLC dengan LED dan phototransistor tunggal. Untuk memperkuat sinyal informasi yang akan dikirim maupun yang akan diterima dapat digunakan IC 74LS15 Scmitt Triggerhex inverter. Berdasarkan analisis pengujian prototipe, didapatkan hasil bahwa prototipe dapat mengirimkan data dengan baik pada jarak $100 \mathrm{~cm}$ dengan kecepatan $4800 \mathrm{bps}$.

\section{DAFTAR RUJUKAN}

D-sub 9 Connector Pinout. https://www.db9pinout.com/, 7 Oktober 2017. 
Denny Setiawan. 2010. Alokasi Frekuensi, Kebijakan dan Perencanaan Spektrum Indonesia. Jakarta: Departemen Komunikasi dan Informatika.

Keiser, G. 2000. Optical Fiber Communications, $3 r d \quad E d$. Boston: McGraw Hill.

Meshram, S.J \& Wadhe, A.P. 2016. Secure data transfer using visible light communication Technique. IJIERE, Vol. 3.
Presiden Republik Indonesia. 2009. UndangUndang Republik Indonesia Nomor 1 Tentang Penerbangan. Pasal 54 poin $\mathrm{f}$.

Sajan, L \& Mathew, L. 2015. Wireless Data Transfer Using Visible Light Communication. IJRET, Vol. 4.

Wu, C \& Zhang, H. 2014. On Visible Light Communication Using LED Array with DFT-Spread OFDM. IEEE.

Yudhabrama, N. 2017. Perancangan dan Analisis Pengiriman Data Digital Berbasis Visible Light Communication.Bandung. 